16.

\title{
THANATOPOLITIKA I IMORTALIZAM \\ U DESNIČINU \\ PRONALASKU ATHANATIKA
}

\section{Vinko Drača}

UDK: 821.163.42-311.9Desnica, V.:612.013-047.64

Izvorni znanstveni članak

Sažetak: Pronalazak Athanatika, skica za distopijski roman Vladana Desnice, problematizira pronalazak lijeka koji može učiniti ljude besmrtnima. U ovom radu pokušat će se dokazati kako problem primjene athanatika kao svojevrsnog „eliksira vječne mladosti“, kako je predstavljen u Pronalasku Athanatika, zapravo proizlazi iz sredstava kontrole nad populacijom koje vlade primjenjuju kako bi ograničile širenje lijeka. U samom djelu razlozi ograničavanja širenja lijeka namjerno proizlaze iz upitne neomaltuzijanske pozicije, koja zapravo prikriva želju vladajućih elita, najbolje personificiranih u diktatoru Mamanu/Mamonu, da prigrabe potpunu kontrolu nad životom i smrti stanovništva s pomoću athanatika kao imortalističke tehnologije. Analizom pojmova imortalizma, biopolitike i iz njega izvedenog pojma thanatopolitike nastojat će se prikazati politička dimenzija tehnologije besmrtnosti onako kako je izražena u djelu te će se na temelju te analize pokušati doći do slike političke moći i čovjeka kao političkog bića u Pronalasku Athanatika.

Ključne riječi: Vladan Desnica, thanatopolitika, biopolitika, imortalizam, Athanatik, besmrtnost, moć, distopija

\section{Mammon i POlitičKa Religija: PronalaZAK ATHANATIKA KAO DISTOPIJSKA PROZA}

\footnotetext{
Dronalazak Athanatika prvi je put, u nešto kraćem izdanju, objavljen 1957. godine u časopisu Literatura. ${ }^{1}$ To smješta objavljivanje ove „skice za roman“ pred kraj tridesetogodišnjeg zlatnog razdoblja distopijske književnosti, koje počinje objavljivanjem $\mathrm{Vr}$ log novog svijeta Aldousa Huxleyja 1932. godine, a završava Paklenom narančom Anthonyja Burgessa, objavljenom 1962. Taj trend distopije u visokoj i popularnoj književnoj kulturi nastavit će se u šezdesetima u okviru sve popularnijeg žanra znanstvene fantastike, a većina

1 Krešimir Nemec, „Pronalazak Athanatika - između utopije i distopije“, u: Vladan Desnica, Pronalazak Athanatika, Zagreb 2006., 85.
} 
ključnih djela iz tog perioda dobit će svoje holivudske adaptacije i učiniti distopiju općim mjestom u zapadnjačkom promišljanju svijeta i budućnosti. Ono što se ističe kao zajedničko gotovo svim distopijama nastalim u ovom periodu jest korištenje razvijenom tehnologijom za bolji nadzor populacije: taj motiv javlja se od naprednih sredstava biološkog inženjeringa i subliminalnih poruka u Vrlom novom svijetu, preko telekrana u 1984. Georgea Orwella, do kontrole ponašanja pojedinaca s pomoću klasičnog fiziološkog uvjetovanja u Paklenoj naranči. Pisci distopija opsjednuti su kontrolom, načinima na koje se neograničena moć može protezati i do najmanjeg i najbeznačajnijeg aspekta ljudskih života. Uloga je tehnologije u tom procesu uvijek asimetrična - dok brojne znanstvene utopije nastale u tom vremenu prezentiraju optimističnu viziju tehnološkog napretka, u distopijama tehnologija služi postojećim hijerarhijama, koje se trude učiniti je nedostupnom običnom čovjeku: ona je oruđe koje se usavršava i razvija s ciljem učinkovitijeg očuvanja statusa quo.

Tehnologija u svijetu Pronalaska Athanatika možda nije tako detaljno opisana kao u brojnim drugim znanstveno-fantastičnim romanima; kao i u Orwellovoj 1984., ona se bazira na jednom tehnološkom otkriću - lijeku protiv smrti. Priču o lijeku protiv smrti pripovjedaču govori stanovito „paranoidno pričalo“, odnosno „krezubi vjetrogonja“ za vrijeme jednog dugog kišnog poslijepodneva. ${ }^{2}$ Postavljena je kao skica za roman, odnosno kao razgovor pripovjedača s Krezubim, autorom tog romana. Tijekom cijele radnje pripovjedač iskazuje cinizam prema temi planiranog djela i prema filozofskim promišljanjima na kojima se zasniva radnja: ponegdje se čini kao da Desnica tom pričom izvrgava podsmijehu neke od apokaliptičnih premisa o ljudskoj budućnosti, a nekad kao da uistinu propituje ulogu smrtnosti u političkoj misli. Sâm athanatik proizveden je u jednoj „fantastičnoj zemlji“, u kojoj su već prethodno riješeni svi „socijalni, ekonomski i slični problemi“. ${ }^{3} \mathrm{U}$ priči, doduše, ne znamo ništa o znanstveno-tehnološkim ili političkim mehanizmima s pomoću kojih su ti problemi riješeni, ali umjesto toga dobivamo opis „lijeka za smrt“. Athanatik je sredstvo čija je proizvodnja nevjerojatno jeftina. Budući da se proizvodi od „prezrene, krajnje jeftine materije“, „vrijednost dviju cigareta bolje vrste, približno odgovara cijeni triju ampulica Athanatika". Jedino mu je ograničenje to da mora biti pažljivo doziran jer u manjim dozama uzrokuje neugodnosti i biva potpuno neefikasan. ${ }^{5}$ Unatoč takvoj maloj cijeni proizvodnje i percipiranoj blagodati za čovječanstvo, masovna proizvodnja athanatika nikad nije zaživjela jer je athanatik podvrgnut rigoroznoj kontroli. Potreba za tom kontrolom, čini se, postoji isključivo iz egzistencijalnih i maltuzijanskih strahova. Kako ističe Krezubi: „Vi dobro znate da po ljudskim zakonima mišljenja pravo da zauvijek traju imaju samo stvari koje oduvijek postoje." ${ }^{\text {" }}$

Čini se da u svijetu athanatik koncepcija „postojanja“ mora imati početnu i konačnu točku, odnosno mora biti omeđena. Nažalost, Krezubi nije detaljnije pojasnio iz koje tradicije izvlači svoje „ljudske zakone mišljenja“, već samo da postojanje koje se proteže u be-

\footnotetext{
V. Desnica, Pronalazak Athanatika, 7.

Isto, 10 .

Isto, 20 .

Isto, 14 .

6 Isto, 21.
} 
skraj samo na jednoj strani, tj. koje ima početak, ali ne i definiran kraj, smatra zazornim: „Kako vi to zamišljate, čemu bi sličila ta vječnost, na jednom kraju zatupljena kao lenjir, a na drugom zašiljena kao strijela."

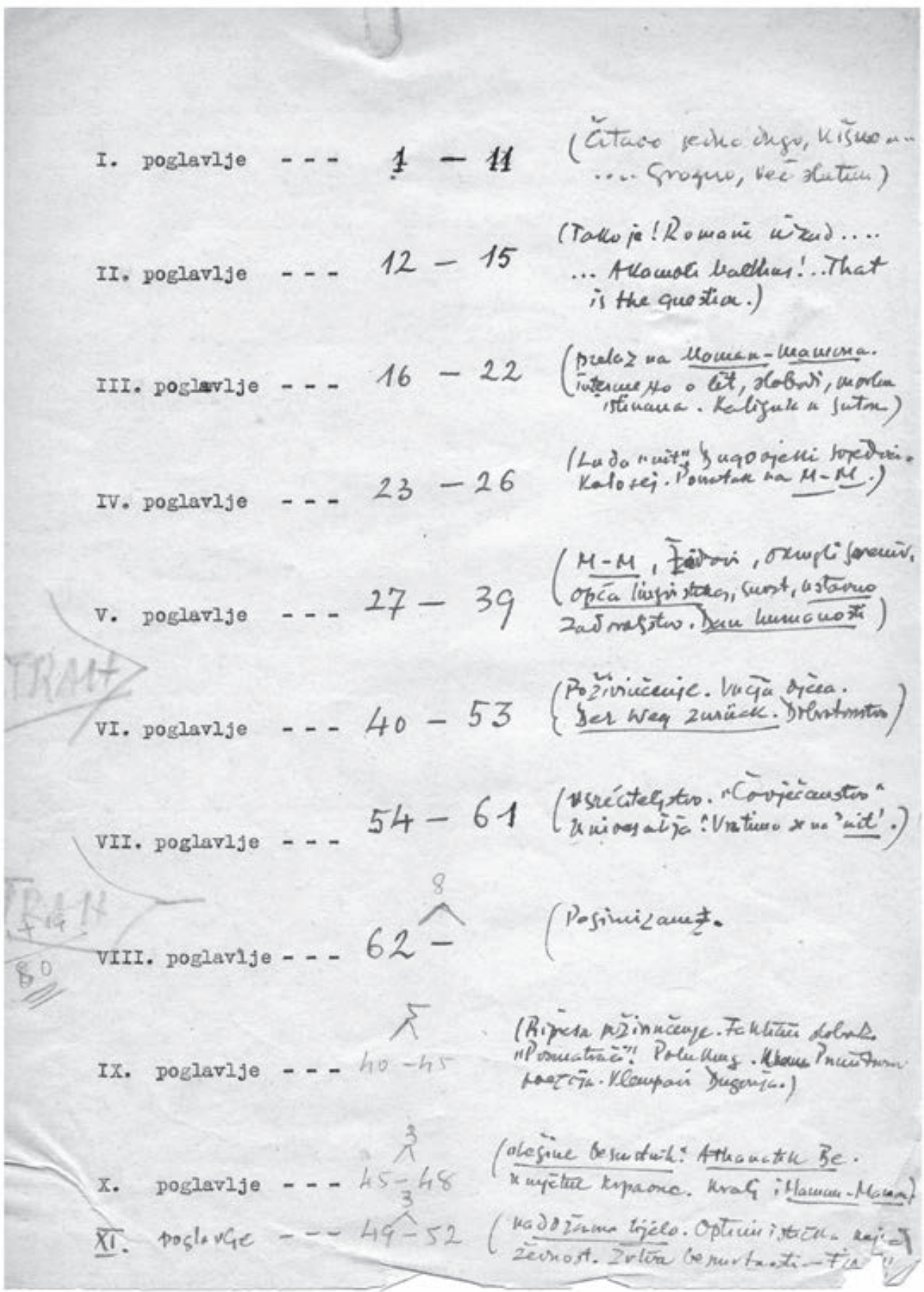

Sl. 1. Pregled poglavlja nedovršena romana Pronalazak Athanatika 
Teško, doduše, možemo zamisliti da je pozivanje Krezubog na neke nedefinirane „ljudske zakone mišljenja“ ovdje slučajno. Čini se da sama ta konstrukcija, kojom se Krezubi koristi kako bi naturalizirao potrebu za kontrolom athanatika unutar svog nenapisanog romana, zapravo služi razotkrivanju ideološkog karaktera te kontrole. Kako bismo lakše vidjeli na koji se način s pomoću ovog citata naznačuje prisutnost političke ideologije kao pokretača radnje u Pronalasku Athanatika, moramo se na trenutak odmaknuti i vidjeti kako taj citat možemo gledati kao iskaz tipičan za religijsko mišljenje te pokušati iznaći poveznicu između religijskog i političkih simboličkih sustava u okviru suvremenih kritičkih proučavanja ideologije.

Prema antropologu Cliffordu Geertzu, religijom možemo nazvati onaj simbolički sustav koji nastoji proizvesti snažna, sveobuhvatna i dugotrajna raspoloženja i motivacije u ljudima formulirajući koncepcije generalnog reda postojanja te zaodijevajući ih u auru činjeničnosti tako da se raspoloženja i motivacije čine jedinstveno stvarnima. ${ }^{8}$ Osjećaj straha i zebnje koju otkriće athanatika prema Krezubom proizvodi u masama i zbog kojeg je njegova proizvodnja ograničena, a primjena podložna političkoj kontroli, ${ }^{9}$ utemeljen je na općenitom zaključku kojim je postojanje kategorija ili vremena zadano definiranim početkom i krajem ili potpune bezvremenosti koja funkcionira onkraj povijesnih kategorija „početka“ $\mathrm{i}$ „Završetka“. Taj pogled na svijet bit će ekspliciran u ustanovljenju religijskog reda „Bratstva poniznih“, koje biva formirano kao reakcija na otkriće besmrtnosti i čija slika svijeta počiva na tabuiziranju geometrijske forme kruga koji za njih predstavlja ljudsku oholu želju da spozna beskonačnost u kojoj se početak i kraj stapaju..$^{10}$ Čini se da je ograničenost ljudske egzistencije ovdje nametnuta kao svojevrsna ideološka koncepcija stvarnosti koja se dovodi u pitanje otkrićem athanatika i koja se onda mora reetablirati kao stvarnija stvarnost s pomoću ritualne zabrane kruga u okviru religije „Bratstva poniznih“. No, taj „ljudski zakon mišljenja“ kao eksplicitno religijska dogma počinje egzistirati tek nakon što nelagoda zbog postojanja athanatika rezultira porastom vjerskog fanatizma - potreba za političkom kontrolom athanatika postoji i prije i čini se da je posljedica određenog maltuzijanizma koji Krezubi također smatra samorazumljivim:

A što bi tek značilo kad bi se ljudski vijek produžio, neću da kažem ad infinitum, ali za samih petnaest ili dvadeset godina. Ta čovječe u roku od par decenija ova bi planeta morala da istodobno hrani dvije, tri, četiri kompletne garniture čovječanstva! A gdje bismo se tek našli za pet, za šest, za deset decenija? Kalifova šahovska tabla s početnim ulogom od zrna pšenice! A kamoli Malthus, moj gospodine! ${ }^{11}$

Svijest o ograničenosti resursa koje zemlja može pružiti populaciji još je jedna ekonomsko-politička dogme na temelju koje se, uz egzistencijalnu dogmu o nužnoj ograničenosti čovjekova postojanja, athanatik ne može neograničeno primjenjivati. Kritike su maltuzijanskih i neomaltuzijanskih koncepcija egzistencije brojne i mnoge su od njih bile prisutne

\footnotetext{
Clifford Geertz, The Interpretation of Cultures, New York 1973., 90.

V. Desnica, Pronalazak Athanatika, 10.

10 Isto, 64-65.

11 Isto, 21.
} 
i u Desničino vrijeme - ideja da besmrtnost znači nekontroliran rast populacije i da rast populacije automatski rezultira nestašicom resursa daleko su od zdravorazumskih, no bez ulaženja u njihovo sveobuhvatno opovrgavanje, kontekst u okviru kojeg su spomenute od strane krezubog paranoika daje naslutiti da su one ideološke prirode i da služe tek kao racionalizacije kontrole nad athanatikom. A kako bi se bolje analizirala priroda te kontrole nad besmrtnošću i vidjelo kako sâm athanatik tom istom logikom postaje sredstvo kontrole, trebamo posegnuti za Foucaltovim pojmom „biomoći“.

\section{BiOMOĆ, IMORTALIZAM I ATHANATIK}

U svojoj seriji predavanja „Društvo se mora zaštititi“, održanoj na Collège de France 1975. i 1976. godine, Michel Foucault uvodi pojmove „biomoći“ i „biopolitike“ kako bi opisao pojavu novih mehanizama kontrole koji se u zapadnom društvu javljaju krajem osamnaestog stoljeća. Pri tome značajna je transformacija iz moći suverena u moć nadzora te moći nadzora u biomoć. Razliku iz tih koncepcija moći možemo jasno pratiti u Foucaultovoj periodizaciji. Moć suverena na način na koji je opisana u Levijatanu Thomasa Hobbesa izvire iz koncepcije države kao tijela koje na neki način u sebi objedinjuje cjelokupnu populaciju i sve funkcije potrebne za upravljanje istom:

Jer umijećem je stvoren onaj veliki LEVIJATAN, nazvan ZAJEDNICOM ili DRŽAVOM (na latinskom CIVITAS), koja nije ništa drugo do umjetni Čovjek, premda je većeg stasa i jačine od onoga prirodnog, čijoj zaštiti i obrani je namijenjena; u njemu je vrhovna vlast umjetna duša, jer daje život i kretanje čitavome tijelu; suci i drugi službenici sudbene i izvršne vlasti su umjetni zglobovi; nagrada i kazna su živci (koji vezuju svaki zglob i ud za sjedište vrhovne vlasti i potiču ga na vršenje svoje dužnosti), jer vrše isto i u prirodnome tijelu; imutak i bogatstvo svih pojedinih dijelova su snaga, njezina namjena je salus populi (dobrobit naroda); savjetnici su pamćenje koje pruža sve stvari nužne za znanje; pravda i zakon su umjetni razum i volja; sloga je zdravlje; pobuna je bolest, građanski rat je smrt. I konačno, sporazumi i ugovori putem kojih su najprije bili stvoreni udovi ovoga političkog tijela, nalikuju, kad ih se skupi i ujedini, onome fiat ili „Stvorimo čovjeka!“ koje je Bog izgovorio pri stvaranju. ${ }^{12}$

Foucault postulira da je Hobbesov koncept suverene vlasti kao duše jedinstvenog tijela zapravo model vladanja zemljom i proizvodima zemlje, a ne ljudima ili populacijom: jedinstveno tijelo zato obuhvaća administrativna tijela, imutak i bogatstvo te sve pravne i političke elemente društvenog ugovora; ono osigurava simboličku apsolutnu moć kojoj se pokoravaju svi sustavi unutar države, ali ne predviđa unificirajući i kontinuiran sustav nadzora koji bi osiguravao djelovanje tih sustava i njihovu direktnu primjenu na populaciju. ${ }^{13}$ Krajem sedamnaestog i početkom osamnaestog stoljeća Foucault percipira nastanak nove vrste moći - moglo je se percipirati još ranije u samostanima i školama, no usavršavanjem

$\overline{12}$ Thomas Hobbes, Levijatan ili grada, oblik i moć crkvene i gradanske države, Zagreb 2004., 11.

13 Michel Foucault, „Society Must Be Defended“. Lectures at the Collège de France 1975-1976, New York $2003 ., 36$. 
tehnika moći ona učinkovito prožima sve aspekte društva. Radi se o moći nadzora nad tijelima kako bi se osigurala njihova puna produktivnost. ${ }^{14}$ Moć nadzora nad individualnim tijelima širenjem sustava kontrole poput državnih cenzusa, popisa stanovništva, javnu medicinu i uvođenje popisa vojno sposobnih stanovnika u svrhu novačenja pretvara u moć koja za svoje subjekte ima cjelokupne populacije. Promjenom kvalitete te moći mijenja se i način na koji ona djeluje na same koncepte života i smrti.

Moć suverena bila je tradicionalno moć nad životom i smrti svojih podanika, no moć nad životom i smrti zapravo ovdje znači upravljanje samo jednim aspektom te binarne opozicije: označava pravo suverena da oduzme nekom život, odnosno da ga ubije. Tu se ne radi o moći da se život podari ili da se pojedincu ili populaciji osigura smrt, već jednostavno o pravu da se ili nekome život oduzme ili ga se pusti da živi. ${ }^{15}$ Biomoć, koja se manifestira potpunijom kontrolom populacije kao tijela (prije svega, njezinom klasifikacijom, segmentiranjem i statističkim opisivanjem svih tijela unutar populacije, na čemu se konstruira jasno opisiva ideja biološkog čovjeka) ima moć izgradnje i oblikovanja života ili njegova onemogućivanja mjerama kontrole populacije. ${ }^{16}$ Jedino utemeljenjem razrađenih i minucioznih sustava kontrole nad populacijom moglo se intencionalno prouzročiti pomore poput Holokausta i Holodomora - moć suverena bila je ograničena na direktnu primjenu sile protiv individualnih tijela, dok biomoć uspijeva djelovati na tijelo populacije s pomoću indirektnih mehanizama nadzora koje nazivamo biopolitikom.

U Pronalasku Athanatika Desnica se koristi žanrom spekulativne fikcije kako bi istražio granice biopolitike koja funkcionira pod uplivom nove tehnologije - one koja omogućuje neograničeno produljenje života. To nije jedino djelo u kojem se Desnica poigravao tim konceptom. Kratka priča Benta Gušter govori o učenjaku koji otkrije lezardin, lijek za sve bolesti, da bi naposljetku počeo spekulirati o načinima izbavljenja besmrtne i uzdignute ljudske vrste ,jednom unitarnom naukom uništenja “. ${ }^{17} \mathrm{U}$ nedovršenoj noveli Čovječanstvo problematiziraju se, pak, problemi altruizma i etike odgovornosti kroz lik znanstvenika Albina koji radi na novom revolucionarnom lijeku ${ }^{18}$. No, tek u Pronalasku Athanatika Desnica dovodi imortalizam u vezu s političkom tehnologijom kontrole. Prije nego što se ekspliciraju tehnologije kontrole koje se u predlošku koji iznosi Krezubi ispleću oko athanatika, treba se detaljnije pozabaviti imortalizmom kao granom transhumanističke i futurološke misli, kao i specifično političkim aspektima imortalizma.

Dvanaestog siječnja 1967. godine dr. James Bedford, umirovljeni profesor na Odsjeku za psihologiju na Sveučilištu u Californiji (University of California), preminuo je nakon komplikacija izazvanih zatajenjem bubrega. Nekoliko trenutaka nakon smrti postao je prva osoba čije je tijelo stavljeno u krioničku suspenziju. ${ }^{19}$ Neprofitna organizacija Alcor Life Extension Foundation danas broji 152 osobe u krioničkoj suspenziji, dok na nju čeka više

\footnotetext{
Isto, 242.

15 Isto, 240-241.

16 Isto.

17 Vladan Desnica, „Benta gušter“, Pripovijetke (= Sabrana djela Vladana Desnice, knj. III), Zagreb 1974., 364.

18 Isti, „Čovječanstvo“, Pripovijetke, 452.

19 Mike Darwin, „Dear Dr. Bedford (and those who will care for you after I do)“ (http://www.alcor.org/Library/html/ BedfordLetter.htm).
} 
od 1500 ljudi. ${ }^{20}$ Tijela tih ljudi zamrznuta su neposredno nakon smrti kako bi se očuvala i kako bi ih se moglo oživjeti jednog dana kada medicina bude napredovala dovoljno da izliječi bolesti od kojih su preminuli i kad im medicinska tehnologija bude omogućila produljenje života. Krionička tehnika očuvanja tkiva blizu je onome što bi se danas moglo smatrati athanatikom - tehnološko sredstvo koje jednom u budućnosti omogućuje tjelesnu besmrtnost. Unatoč povoljnim cijenama (zamrzavanje čitavog tijela stoji oko 23000 dolara), malo se ljudi odlučuje na taj korak i čini se da nema nikakvih ozbiljnijih pokušaja da se ova imortalistička tehnologija stavi pod bilo kakav oblik kontrole. Većinu troškova obitelji pacijenata financiraju same, najčešće policama zdravstvenog osiguranja, a sam Alcor spreman je korisnicima izaći u susret u pogledu bilo kakvih pravnih poteškoća. Čini se da se distribucija krioničkog athanatika zbivala uglavnom logikom individualne inicijative i povremenih grassroots akcija, kojima su se prikupljala sredstva za očuvanje tijela onih pojedinaca koji nisu mogli podmiriti troškove.

Druge vrste tehnologija koje za cilj imaju produljenje ljudskog života, poput terapija protiv starenja i regenerativnih biomedicinskih teorija, nisu izazvale niti ontološku krizu niti zabrinutost zbog maltuzijanske prenapučenosti. Čini se da onaj dio znanstvene zajednice koji vjeruje da je eliminacija starenja i smrti moguća, također misli da je konačna eliminacija starenja i smrti poželjan cilj te je samim time na tragu svih mitova i predaja koji dosezanje tjelesne besmrtnosti ističu kao ljudsku žudnju. Ta žudnja u predajama, poput one o Ahsaveru ili pak Ukletom Holandezu, često nosi stigmu prokletstva: biti Vječan na neki način znači biti nepotpun, otuđen od vlastitog vremena i suočen $s$ egzistencijalnom nelagodom koju uzrokuju ahistoričnost i atemporalnost pojedinca naviknutog na linearno poimanje vremena koje kao krajnju kategoriju uključuje prolaznost, tako da ipak unutar znanstvene zajednice postoji i značajan otpor toj ideji. ${ }^{21}$

Većina imortalističkih koncepata uopće ne raspravlja o političkom potencijalu lijeka protiv starenja, no Desnica je, čini se, prvenstveno zabrinut zbog načina na koji taj lijek može poslužiti kao novo sredstvo kontrole nad populacijom. Kada govori o sredstvima kontrole, pisac fantastičnog romana uvodi podjelu na zemlje „liberalističkog tipa“22 i totalitarnu diktaturu kojom upravlja vlastodržac po imenu Maman/Mamon. ${ }^{23}$ Međutim, Desničin Krezubi sâm će tu dihotomiju ubrzo predstaviti kao lažnu, iznoseći skepsu u stvarno postojanje istinske demokracije i slobode:

Jest, sloboda vjere i savjesti, zbora i dogovora, ličnog uvjerenja i privatne inicijative; pravo na neslaganje, na odvojeno mišljenje, na štrajk, na pobunu čak. Figu! Znam ja iz iskustva kako to u praksi izgleda! A priori sam skeptičan prema svakoj obilaštini u takvim stvarima. Te „slobode“ tako u pluralu, pobuđuju opravdano podozrenje, kao i svaka doping roba. ${ }^{24}$

20 Alcor Membership Statistics (http://www.alcor.org/AboutAlcor/membershipstats.html).

21 Za neke aspekte rasprave o biotehnologijama i besmrtnosti usp. Elvio Baccarini, In a Better World? Public Reason and Biotechnologies, Rijeka 2015., 101-115.

22 V. Desnica, Pronalazak Athanatika, 22.

23 Isto, 34.

24 Isto, 22. 
Čini se da te liberalne demokracije athanatika kontroliraju pravnim mehanizmima kategoriziranja stanovništva u kojem postoji jasna hijerarhija po kojoj građani ostvaruju pravo na besmrtnost:

Tek, ovako ili onako, na temelju ove ili one državnopravne teorije, u svim je zemljama podjednako šefu države priznata ta prerogativa. Stvorena je pravna ustanova „Izuzeća od smrti" takozvani Todesenhebung kako su to tehničkim terminom nazvali njemački autori, koji su taj pravni pojam do u tančine razradili i dali najvrednije radove na tom području. Za šefom države slijedio je niz velikodostojnika: predsjednici ministarskih savjeta, predsjednici predstavničkih tijela, predsjednici akademija i instituta, nosioci najvećih odlikovanja s mačevima i lentom. Zatim ministri i državni podsekretari, redovni akademici, rektori i prorektori, predsjednik kasacije... ${ }^{25}$

U ovakvoj kategorizaciji vidimo da pravni instrumenti kojima je suverena vlast prigrabila pravo distribucije athanatika omogućuju suverenoj vlasti dosad neviđeno polje na kojima može manifestirati svoju biomoć: za razliku od Foucaultova suverena, koji je život mogao ili oduzeti ili ne oduzeti, i biopolitičke vlasti, koja je mogla poticati ili onemogućiti život slojevima populacije, nova vlast ima mogućnost podariti besmrtnost ili „osuditi“ pojedine dijelove populacije na smrtnost. Pravni karakter kontrole prisutan u državama „liberalističkog tipa" odgovara mehanizmima kontrole, prisile i prinude koje pretvaraju Benthamov panoptikon u poželjnu formulu liberalnog vladanja. ${ }^{26}$ Državne mehanizme ekonomske intervencije ovdje zamjenjuje država, koja za svoju primarnu svrhu ima provođenje legalističkih mjera koje služe kao protuteža slobodama.

Ovdje je na djelu biopolitička metoda razdvajanja mnoštva tijela u segmente, no za razliku od klasične biopolitike, koja priznaje smrt kao entitet koji je izvan njezine domene i koja je samim time relegirana u sferu privatnog, ${ }^{27}$ ovdje postoji moć da se smrt eliminira i da se biopolitičkim mjerama život omogući samo određenim kategorijama ljudi. Smrt je ovdje očito predmet javnih politika, a besmrtnost postaje sinekurno dobro koje vlast razrađenim pravnim mehanizmima - koji su, kako smo već naglasili, u svojoj biti biopolitički - dodjeljuje zaslužnima. Hijerarhijska nejednakost inherentna etatističkim sustavima ovdje postaje upravo brutalno evidentna, riječima Krezubog iz Desničine skice za roman:

Zinula je među dvonošćima provalija kakva nikad ranije nije postojala - eto što je bilo. Ljudi su se dijelili, ne više na imućne i siromašne, na site i gladne, na gospodare i besmrtne. Sto ćete gore dobri moj gospodine!... ${ }^{28}$

Nakon što je athanatik na ovako direktan način učinio razvidnim hijerarhijski karakter demokratskih društava, a pravnu znanost i njezine sustave razobličio kao instrument perpetuiranja te nejednakosti, Krezubi nastavlja opisivati kako se athanatik distribuirao u jednoj totalitarnoj zemlji, kojom je vladao diktator dualnog imena Maman/Mamon. Mamanova autokratska država podvrgnula je distribuciju athanatika samom Mamanu, koji je „Atha-

\footnotetext{
25 Isto.

26 Usp. Michel Foucault, Rođenje biopolitike, Zagreb 2016., 75.

27 Isti, „Society Must Be Defended“, 248.

28 V. Desnica, Pronalazak Athanatika, 22.
} 
natik izuzeo iz kategorije znanstvenih pronalazaka i lijekova i uvršten u red odlikovanja za društvene zasluge“, ${ }^{29}$ koje se moglo dodjeljivati jedino herojima. No, kako svaki heroj ima vremena do smrti počiniti izdaju, athanatik se smio dodijeljivati jedino post mortem. Sâm diktator javno nikad nije uzeo athanatik, no pio je koktel složen od lijeka za besmrtnost i „stare manastirske prepečenice“, iako oralno uzimanje lijeka nije imalo nikakva efekta. ${ }^{30}$ Također, razvijen je novi lijek koji poništava učinak athanatika i uvedeno obvezno cijepljenje njime za sve građane.

Tipične kategorije biomoći prisutne su i u totalitarnom društvu, no ovdje athanatik omogućuje nešto novo: činjenica da je vladar tjelesno besmrtan (do kraja Krezubi nije otkrio je li vladar uzeo lijek ili ne) omogućuje fizički kontinuitet suverenova tijela i tako premošćuje jedini nedostatak neograničene vlasti suverena kakvu je zamislio Hobbes. Neograničeno fizičko postojanje suverena tako može doslovno rezultirati koncentracijom apsolutne moći u jednoj osobi. ${ }^{31}$ Budući da ta osoba jedina upravlja medicinskom tehnologijom besmrtnosti, ona de facto postaje Hobbesovim idealnim suverenom, dušom države koja ima kontrolu kako nad životom (može nekom dodijeliti čast athanatika) tako i nad smrću (jer je odredbom o cijepljenju sve ljude učinio smrtnima), a on ih prema volji može pogubiti.

Opis Mamana u sceni u kojoj dijeli nižim državnim dužnosnicima koktel od athanatika i rakije daje bizarnu i pomalo karikaturalnu sliku apsolutne vladareve moći:

Ako je starac ustao dobre volje, znalo je da bude i veselije. „Bi li i ti liznuo kapljicu, a?“ podmignuo bi svom miljeniku. „Pristupi! Klekni, životinjo!“ Zamočio bi srednjak desne ruke u čašicu. „Na! lizni slone! Pričesti se!“ Diskretan osmjeh u polukrugu. $S$ grimasom gorkog napitka na licu, miljenik pristupa, oblizuje prst. Ostali motaju usnama, gruste se od neugodna lijeka, bajagi sretni što je njih mimoišla dužnost da kušaju nevoljeni aperitiv. ${ }^{32}$

Ako se vlast suverena u feudalno i u doba dvorskog apsolutizma simbolički prikazivala držanjem žezla (simbol fizičke moći i monopola nad silom) i kraljevske jabuke (Globus Cruciger, simbol tjelesnog odražavanja Kristove vlasti nad duhovnom sferom postojanja), ovdje sâm koktel od rakije i athanatika postaje simbol doslovne moći nad životom i smrću. Pronalaskom athanatika, koji završava u rukama nosioca totalitarne vlasti, smrt je opet postala političkim pitanjem, a Maman postao je ultimativnim suverenom sustava političke kontrole.

\section{ZAKLJUČAK: DESNICA I POJAM THANATOPOLITIKE}

Ako utopijski romani služe zamišljanju idealnih društvenih formi koje teže dokidanju nejednakosti, svrha je distopijskih romana pronalaženje tendencija u društvu koje mogu dovesti do opresivnih situacija. U Pronalasku Athanatika do izražaja dolazi svojevrstan politički skepticizam. Bez obzira na način upravljanja državom, sama će država osigurati daljnje

\footnotetext{
Isto, 43.

Isto.

31 M. Foucault, „Society Must Be Defended“, 36.

32 V. Desnica, Pronalazak Athanatika, 45.
} 
perpetuiranje nejednakosti te pretvoriti na prvi pogled poželjnu ideju eliminacije smrti i starenja u sustav aktualizacije društvenih nejednakosti. Biopolitička kontrola, ostanu li odnosi u društvu ovakvi kakvi jesu, u slučaju dostupnosti medicinske tehnologije koja omogućuje fizičku besmrtnost, uskoro prerasta u neograničenu moć vlasti: vlast sad ima sva raspoloživa sredstva kontrole koja joj omogućuju da dijelovima populacije udijeli život. Moć udjeljivanja života kvalitativno se znatno razlikuje od moći suverena - koji može jedino oduzeti život - i biomoći - koja ga u širokom razmjeru može pospješiti ili otežati. Moć da se pozitivno ukine smrt nekih dijelova populacije doslovno dijeli ljude na kategorije „živih“ (onih koji zaslužuju primiti athanatik) i „privremeno živih“ (oni koji nikad ne mogu iskusiti puninu života). Također, postojanje takve moći čini odmak od biopolitike, čini kvalitetu života populacije pitanjem javne važnosti, dok se smrt smještala u područje privatnog jer život slobodan od smrti čini i samu smrt javnim pitanjem. Sam Maman, pretvorivši samog sebe u pomalo karnevalsku sliku besmrtnika i tjerajući funkcionere da kušaju koktel od athanatika, pretvara besmrtnost u javni spektakl, na sličan način na koji su srednjovjekovna i ranonovovjekovna pogubljenja karnevalizirala smrt. U svakom slučaju, biopolitičke mjere uspjele su i smrt, uz život, učiniti javnim pitanjem pa, prema tome, možemo zaključiti da Desnica u Pronalasku Athanatika postulira novi oblik biopolitike - thanatopolitiku.

Definicija bi thanatopolitike, najsažetije, glasila: thanatopolitika je neograničena moć vlasti nad životom i smrti svojih podanika, koja proizlazi iz uspješno provedene kontrole nad tehnologijom koja omogućuje fizičku besmrtnost. Cilj je thanatopolitike s pomoću tehnologija nadzora klasificirati pojedinačna tijela svojih podanika u dvije populacije: onu fizički besmrtnu kojoj je podaren život i onu fizički smrtnu koja je izuzimanjem iz prve osuđena na smrt.

Trenutačno, sredstva učinkovitog produžetka života ne postoje, a tehnologije koje pružaju nadu u besmrtnost, poput krionike, još su u povojima i razvijaju se inicijativom pojedinaca. Problematizacija thanatopolitike, kako je ona prikazana u Pronalasku Athanatika, postat će pitanje od presudne društvene važnosti ako jednog dana sredstva produljenja života postanu medicinskom činjenicom. Ta tehnologija, ako je znanost bude razvila, bit će jedna od onih koja će nas definitivno natjerati da promislimo odnos između vlasti i populacije nad kojom se mehanizmi te vlasti provode.

\section{$\cos$}

\section{Literatura}

Elvio Baccarini, In a Better World? Public Reason and Biotechnologies, Rijeka 2015.

Vladan Desnica, „Benta gušter“, Pripovijetke (= Sabrana djela Vladana Desnice, knj. III), Zagreb 1974., 356-367.

Vladan Desnica, „Čovječanstvo“, Pripovijetke (= Sabrana djela Vladana Desnice, knj. III), Zagreb 1974., 450-455.

Vladan Desnica, Pronalazak Athanatika, Zagreb 2006.

Michel Foucault, Rodenje biopolitike, Zagreb 2016. 
Michel Foucault, „Society Must Be Defended“. Lectures at the Collège de France 1975-1976, New York 2003.

Cliford Geertz, The Interpretation of Cultures, New York 1973.

Thomas Hоввеs, Levijatan ili grada, oblik i moć crkvene i gradanske države, Zagreb 2004.

Krešimir Nemec, „Pronalazak Athanatika - između utopije i distopije“, u: Vladan Desnica, Pronalazak Athanatika, Zagreb 2006., 81-94.

\section{Mrežne stranice}

Alcor Membership Statistics (http://www.alcor.org/AboutAlcor/membershipstats.html).

Mike DARwin, „Dear Dr. Bedford (and those who will care for you after I do)“ (http://www.alcor. org/Library/html/BedfordLetter.htm).

\section{$\cos$}

\section{ThanATOPOLITICS AND IMMORTALISM IN DESNiCA'S PRONALAZAK ATHANATIKA}

Pronalazak Athanatika (The Discovery of Athanatic), Vladan Desnica's draft for a dystopian novel, addresses the issue of a discovery of a cure for mortality. This paper demonstrates that the real issue with the application of Athanatic as an elixir of eternal youth, as represented in the novel, arises from the means of controlling the population used by the governments in order to limit the availability of the cure. In the novel itself, the reasons for this are deliberately attributed to a questionable neo-malthusian position which disguises the true motives of the ruling elites - best personified in the character of the dictator Maman/Mamon - to acquire full control over the life and death of the population with the help of Athanatic as an immortalising technology. An analyisis of the concepts of immortalism, biopolitics and its derivative, thanatopolitics, reveals the political dimension of the technology of immortality as depicted in the novel, providing insight into the novel's depiction of political power and humans as political beings. Considerations of biopolitics and immortalist technologies gain significance in view of the resources and the labour invested in the development of life extention technologies by the scientific community. With this in mind, public health policies and control over medical technologies must be assessed in new ways, so that we can be prepared foaddressing the social challenges that new technologies will set before us. Great speculative fiction like Desnica's Pronalazak Athanatika can allow us partial insight into the political problems that might arise from the availability these, as of yet, futuristic technologies.

Key words: Vladan Desnica, thanatopolitics, biopolitics, immortalism, Athanatic, immortality, power, dystopia 
